\title{
Por hondo que sea el mar profundo...
}

\author{
Miguel Ángel Hinojosa Carranza
}

\begin{abstract}
A JoAQUín
[...] y me dije: voy a guardar intacto el recuerdo de este instante porque todo lo que existe ahora mismo nunca volverá a ser igual.

Un día lo veré como la más remota prehistoria.
\end{abstract}

(JEP, 1981:31).

Las batallas en el desierto ${ }^{1}$ es un péndulo en el tiempo, un constante ir y venir entre el pasado que se añora, al presente que se diluye en un instante y el futuro anhelado; mininovela o cuento largo que se ha tornado clásico, eterno. En sus páginas podemos leer, entre infinidad de posibilidades, lo que permanece del ser humano, la bondad y la maldad, el amor y el odio, vida y muerte, alegrías y tristezas, egoísmo y empatía; todo ello en el enamoramiento y el impulso por la libertad de un niño-joven que se enfrenta ante el actuar atroz del dominio, del control y la sujeción conservadora de una familia y una sociedad clasista, xenófoba, racista, homófoba y por lo mismo, extremadamente machista, además encontramos esa eterna ambivalencia de gente que se mueve entre parámetros contrapuestos, "lo moral" y "lo inmoral", "lo correcto y lo incorrecto", lo permitido y lo prohibido, lo que los convierte en víctimas y victimarios..., hipocresía total. De igual modo, el libro nos habla de esa pasión que se tiene tanto en México por el consumismo y por el capital, por el ansia del desarrollo, de la prosperidad económica que nunca llega, y si lo hace es sólo para unos cuantos, porque la gran mayoría se queda estancada en la frustración y la pobreza disfrazadas por miles de caras.

${ }^{1}$ José Emilio Pacheco, Las batallas en el desierto, Ediciones Era, México, 2011, 68 pp. Este 7 de junio de 2020 se cumplieron 40 años de su publicación por primera vez en el suplemento "Sabado", de unomásuno. 
De igual modo, en Las batallas encontramos un país, una ciudad, una colonia, un barrio en el que habitamos que permanece sí, pero que ya no está más, en el que todo ha cambiado para que el mundo siga girando igual. Entrańable colonia Roma que se trasmuta, se multiplica infinitamente en el tiempo y el espacio y que puede tomar la forma de múltiples colonias en la ciudad y en el tiempo: la San Rafael, Santa María la Ribera, la Pénsil o San Juande Aragón, lo importante es que recojan en sus calles, esquinas, casas, edificios, plazas, mercados y escuelas, los cachitos de vida que nos fueron nutriendo, que evoquen el lugar que nos vio nacer y crecer: "Los faroles plateados daban muy poca luz. Ciudad en penumbra, misteriosa colonia Roma de entonces. Átomo del inmenso mundo, dispuesto muchos años antes de mi nacimiento como una escenografía para mi representación” (p. 30).

"Colonia Roma", "Lugar de en medio" donde converge la clase media cada vez más venida a menos, tan cerca de Polanco, Chapultepec, la Nápoles o la Del Valle y también de la Doctores, Romita y la Cuauhtémoc; frontera entre el bienestar y la necesidad, símbolo de la desigualdad social, del eterno padecer de los muchos y la opulencia de unos cuantos, un México chiquito, anhelante de lo que no es y despectivo de su verdadero ser, el mismo que antepone lo extranjero ante lo nacional.

Carlitos, protagonista de la breve novela de José Emilio Pacheco, encarna el deseo y el ansia de libertad de un niño-adolescente que siente el amor más puro, el enamoramiento más profundo que uno pueda imaginar; de joven-adulto, se trastoca en un narrador elocuente que nos remonta a su nińez al contarnos con detalle "el mundo antiguo", sus recuerdos de aquellos tiempos; así, iniciamos con él nuestro viaje en el tiempo a un México de mediados del siglo XX descrito a partir de su círculo personal: familia, compañeros de escuela, maestro y amigos. Carlitos nos habla de lo que comían, bebían, escuchaban o veían en el cine; de las mutaciones que se dieron en sus hábitos, los lujos, los avances industriales o de la tecnología en el hogar: autos nuevos y súper modernos, licuadoras, refrigeradores, estufas, lavadoras, sandwicheras; las novedades en la política, esa eterna cueva de "Alí Babá y los cuarenta ladrones" que en México -ipobre México de entonces y de hoy!- siempre ha sido sinónimo de saqueo y hurto para los gobernantes; igual nos habla de "los desastres de la guerra", de "las infinitas matanzas, los campos de exterminio, la bomba atómica, los millones de muertos", y junto a ello, a unas líneas de distancia solamente, él mismo narra cómo por aquellos tiempos su profesor Rosales imaginaba las maravillas del futuro por venir, cómo sería nuestra sociedad en el año 2000, tan lejano en ese ayer como ahora en nuestro presente: "el mundo de mañana, el mundo en el que ustedes serán hombres, debe ser un sitio de paz, un lugar sin crímenes y sin infamias" (p. 13). Bendita utopía, anhelo de ayer y hoy siempre postergado. 
Pero la "Obsesión" de Carlitos, el verdadero motivo que le hace rememorar tan vívidamente aquellos ańos no es otra cosa sino el amor, porque por más obstáculos que nos pongan el tiempo y la distancia, las normas sociales y la "educación" familiar, el dinero o la falta de éste, por más que se piense que todo ha pasado, uno siempre regresa, aunque sea por un instante y por mera casualidad, "al lugar donde ha sido feliz" y entonces todo empieza: "Me acuerdo, no me acuerdo: ¿qué año era aquél?" (p. 9). Así, el joven narrador regresa al tiempo cuando era nińo y el círculo se cierra; comprende que el amor es el combustible que mueve infinitamente la máquina de la vida, y aunque se diga a sí mismo que "el amor es una enfermedad en un mundo en que lo único natural es el odio" (p. 56), sabe lo que la vida le ha enseńado, que todo es fugaz pero permanente, aun cuando dude de su memoria y de su razón, porque eso hace el amor, cuestionarnos todo. Esta breve novela, con su sencillez y sus pocas páginas, es tan grande, perdurable, enorme y entrañable, tan honda en el corazón, como el mar más profundo, y si no ¿por qué será que seguimos leyéndola una y otra vez? $\mathrm{Al}$ igual que seguimos tarareando en nuestro interior... "Por alto esté el cielo en el mundo, por hondo que sea el mar profundo, no habrá una barrera en el mundo que mi amor profundo no rompa por ti". 



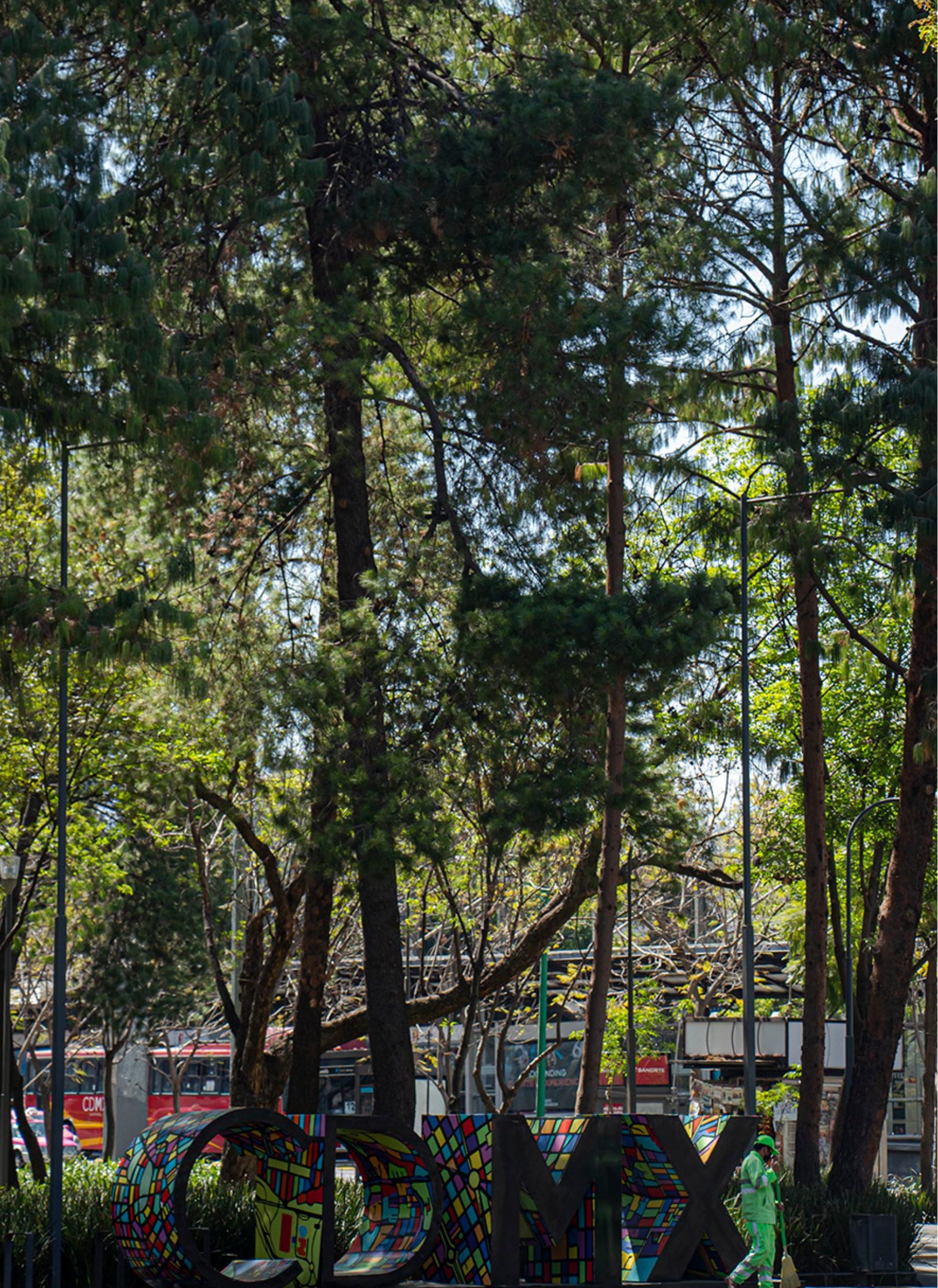


Fotografía | Iraís Hernández Güereca 